\title{
Medical Weight Problem Diagnosis and Minority Women's Desire for Thinness
}

\author{
Olvera $\mathbf{N}^{1 *}$, Posada $\mathrm{A}^{1}$, Arbona $\mathrm{C}^{1}$, Zhang $\mathbf{R}^{1}$, Butler \\ $\mathrm{A}^{2}$ and Wiesner $\mathrm{M}^{\mathbf{1}}$ \\ ${ }^{1}$ Department of Psychological, Health, \& Learning \\ Sciences, University of Houston, 3657 Cullen Boulevard \\ Room 491, Houston, Texas, USA \\ ${ }^{2}$ Department of Pediatrics, Section of Psychology, \\ Baylor College of Medicine, Director, Health Disparities \\ Laboratory in Pediatric Psychology, CH Feigin Building, \\ 1102 Bates Street, Suite 940, Houston, TX, USA \\ *Corresponding author: Norma Olvera, Department \\ of Psychological, Health, \& Learning Sciences, University \\ of Houston, Houston, TX 77204-5029, USA
}

Received: January 28, 2021; Accepted: February 27, 2021; Published: March 06, 2021

\begin{abstract}
Background and Objectives: Without appropriate medical weight problem diagnosis, minority women might have inaccurate views of their weight status. It is likely that receiving an obesity diagnosis from a physician will raise women's awareness of their weight status and increase their desire or intent to control their weight. This study assessed: (1) the unique and combined contribution of medical weight diagnosis to desire to be thinner among minority women with overweight/obesity; (2) to what extent ethnicity/race moderated the relation of medical weight problem diagnosis to desire to be thinner; and 3) ethnic/racial differences in perceived and ideal body size, and body dissatisfaction among minority women.
\end{abstract}

Methods: 366 Hispanic and 111 African American women with a mean age of 43.7 years $(S D=15.9$ years) completed a self-report health survey and figure rating scale.

Results: Only $34.1 \%$ women reported having received a medical weight problem diagnosis in the past 12 months. Women with obesity (35.4\%) were more likely to have received a medical weight problem diagnosis than women with overweight $(11.8 \%) \quad(p<0.001)$. Hierarchical multiple linear regression analysis revealed an association between a medical weight problem diagnosis $(\beta=0.19, p=0.011)$ and desire to be thinner after controlling for ethnicity/race, researcher-estimated body mass index, and weight concern.

Conclusions: The study's findings provide evidence supporting the significant role that physicians' weight problem diagnosis may play in minority women's desire for thinness.

Keywords: Overweight; Hierarchical; Diagnosis; Ethnicity

\section{Introduction}

Obesity affects one-third of the United States adult population, particularly, Hispanic and African American women [1,2]. The negative physical and psychological consequences of obesity on health and quality of life are well documented [3,4]. Despite the existence of medical guidelines for obesity diagnosis and management for adults [5-8], physicians' efforts to prevent and treat obesity have been challenging $[7,9]$. Between $30 \%$ and $50 \%$ of people with overweight $(\mathrm{PwO})$ are estimated to have received a medical weight problem diagnosis from their primary-care physician $[5,8,10,11]$. The underdiagnosis of obesity in primary care settings $[12,13]$ may suggest to PwO that they do not have a weight problem or that they do not need to seek weight control advice $[14,15]$. Physicians' barriers to providing an obesity diagnosis and weight control advice have been extensively investigated. The identified barriers are mostly related to providers' attitudes (e.g., limited competency in obesity counseling and treatment, beliefs that obesity is PwO's responsibility), and practices (e.g., prioritizing treatment of medical conditions over weight control concerns and limited consultation time with patients) [5,11,16-20]. Despite these barriers, research indicates that physicians' attention to obesity issues helps to increase overweight and obese patients' intention to lose weight, weight loss initiation, and weight loss maintenance $[5,21]$.
Research indicates that Hispanic and African American women are less likely to be diagnosed with a weight problem than their Caucasian counterparts are during a physician visit $[22,23]$. This finding is disconcerting in light of national data which indicated that two out of three Hispanic and African American women were overweight or obese [24]. In addition, minority women with overweight/obesity exhibited greater acceptance of a larger body size [25] and were more likely to underestimate their body size compared to their normal weight peers [27] and Caucasian counterparts [26,28]. Underestimation of body size may lead minority women to be less concerned about their weight status, which may decrease their desire to be thinner and achieve a healthier weight $[11,12,29]$. Without appropriate medical weight problem diagnosis and sound weight control advice, minority women with overweight or obesity might have inaccurate views of their weight status. It is likely that receiving an obesity diagnosis from a physician will raise women's awareness of their overweight or obese status, increase their desire or intent to control their weight [5] and increase their engagement in healthy behaviors to improve their weight status $[30,31]$.

There is a dearth of studies examining the association of medical weight problem diagnosis to body size attitudes (e.g., desire to be thinner) among minority women or the role of ethnicity/race moderating this relationship. Thus, this study aimed to address
J Fam Med - Volume 8 Issue 1 - 2021

ISSN : 2380-0658 | www.austinpublishing group.com

Olvera et al. (C) All rights are reserved
Citation: Olvera N, Posada A, Arbona C, Zhang R, Butler A and Wiesner M. Medical Weight Problem Diagnosis and Minority Women's Desire for Thinness. J Fam Med. 2021; 8(1): 1241. 
this gap in the literature by assessing: (1) the unique and combined contribution of medical weight diagnosis to desire to be thinner among minority women with overweight/obesity; (2) to what extent ethnicity/race moderated the relation of medical weight problem diagnosis to desire to be thinner among Hispanic and African American women with overweight/obesity; and 3) ethnic/racial differences in perceived and ideal body size, and body dissatisfaction among Hispanic and African American women (i.e., regardless of their researcher-estimated Body Mass Index (BMI)). After controlling for key variables, a positive association between medical weight problem diagnosis and desire to be thinner among minority women with overweight/obesity is hypothesized.

\section{Methods}

\section{Participants}

The sample consisted of 477 Hispanic $(n=366)$ and African American $(n=111)$ women. Out of this total sample of 477,242 women were excluded from regression analysis because of missing key variables and 59 women were excluded because they were classified as healthy weight. The inclusion criteria to participate in this study consisted of: 1) identification as a Hispanic or African American; 2) being 18 years or older; and 3) being able to read English or Spanish to complete study instruments. During 2015 and 2017, participants were recruited at four community health fairs held primarily in Hispanic and African American neighborhoods located in a metropolitan region in the Southeast United States. The University's Institutional Review Board approved the study's protocol.

\section{Instruments}

Health survey: The health survey included demographic questions and questions regarding perceived weight status and medical access and weight concern diagnosis. For this study, health survey questions included inquiring about participants' 1) demographic characteristics (e.g., age, gender, ethnicity/race, and income); 2) self-reported weight and height; 3 ) weight concern level (e.g., "How concerned are you about your weight?" using a Likert scale ranging from $1=$ not concerned at all to $4=$ extremely concerned); and 4) having received a medical weight problem diagnosis in the past 12 months $(\mathrm{No}=0$, Yes=1). Based on participants' self-reported height and weight, investigators used the weight (kgs.) $/$ height $^{2}$ (meters) Quetelet formula to calculate participants' body mass index (BMI). Using the World Health Organization obesity status classification for adults, participants with a BMI $<18.5$ were classified as underweight, BMI of $\geq 18.5$ to $\leq 24.9$ were classified as of healthy weight, BMI of $\geq 25.0$ to $\leq 29.9$ were classified as overweight, and BMI $\geq 30$ were classified as obese. Previous studies revealed that correlations between selfreported and measured values for weight and height were high $(\mathrm{r}=0.84-0.92)[32,33]$.

Stunkard Figure Rating Scale (SFRS): This instrument was used to assess perceived weight status and ideal body size to determine body size dissatisfaction and desire to be thinner. The Stunkard Figure Rating Scale [34] is comprised of nine silhouette figures of women of increasing body size from very thin (a value of 1 ) to obese (a value of 9). For perceived body size, participants were asked "How do you think you look?" and to select a silhouette that represents their choice. BMI equivalents for the Stunkard female silhouette figures established by Bulik and colleagues [35] were utilized to determine participants' perceived weight status. Based on these equivalents, silhouette 1 corresponded to an average BMI of $18.3(S D=3.0)$, which is equivalent to the underweight category. Silhouettes 2,3 , and 4 corresponded to an average BMI of $19.3(S D=1.7), 20.9(S D=1.8)$, and $23.1(S D=2.2)$ respectively, which are equivalent to the healthy weight category. Silhouettes 5 and 6 corresponded to an average BMI of 26.2 $(S D=3.0)$ and $29.9(S D=3.8)$, respectively, which are equivalent to the overweight category. Silhouettes 7-9 corresponded to an average BMI of $34.3(S D=4.7), 38.6(S D=6.2)$, and $45.4(S D=7.8)$, respectively, which are equivalent to the obese category. To assess ideal body size participants were asked to select the silhouette that represented "the way you would like to look." Body size dissatisfaction was determined by subtracting the score for ideal body size from the perceived body size score. Greater values indicated higher desire to be thinner. The SFRS has demonstrated good test-retest reliability and its scores are positively correlated with female drive for thinness $(\mathrm{r}=0.85)$ and body dissatisfaction $(\mathrm{r}=0.91)$ [36].

\section{Data collection}

Data were collected from Hispanic and African American women who visited a healthy eating exhibit during four community health fairs. One of four approached individuals participated in this study. Upon attending the healthy eating exhibit, potentially eligible Hispanic or African American women were invited to participate in the study and provided information regarding the study's purpose, activities, and time commitment (10-15 minutes). If participants agreed to participate and signed informed consent form, a bilingual research assistant instructed them to complete the health survey and SFRS instrument in their preferred language (i.e., English or Spanish).

\section{Statistical analysis}

To address study aims 1 and 2, first Spearman or Pearson's correlation analyses were conducted to examine the correlations among key variables (not shown). Then, a three-step hierarchical multiple linear regression analysis was performed to assess factors associated with desire to be thinner among the subset of women whose researcher-estimated BMI fell in the overweight or obese range. Only women with overweight or obesity were included in this analysis because these women would have been more likely to receive a medical obesity diagnosis than underweight/normal weight women. At Step 1, the demographic, researcher-estimated BMI, and weight concern variables were entered in the model to assess their contribution to women's desire to be thinner. At Step 2, medical weight problem diagnosis was added to the model. At Step 3, the interaction term of medical weight problem diagnosis by ethnicity/ race was added to examine to what extent ethnicity/race moderated the association of medical weight problem diagnosis to women's desire to be thinner. Logistic regression analysis was employed to predict the probability that a woman with researcher-estimated BMI falling into the overweight or obesity category would receive a medical weight problem diagnosis by a physician. To address aim 3 , Pearson Chi-Square tests were used to assess ethnic/racial differences in perceived and ideal body size, and body size dissatisfaction in the study sample of Hispanic and African American women. Analyses were conducted using SPSS Statistics version 25.0 and statistical significance was set at $\mathrm{p}<0.05$. 
Table 1: Sample Descriptive Characteristics.

\begin{tabular}{|c|c|c|c|c|c|c|c|c|}
\hline Variable & Total Sample N=477 & Hispanic Women $\mathrm{N}=366$ & AA Women $\mathrm{N}=111$ & $d f$ & $t$ & $x^{2}$ & $p$ & Cramer's V \\
\hline Age $M(S D)$ & $43.7(15.9)$ & $40.3(13.2)$ & $54.7(19.0)$ & 475 & 7.44 & & 0.001 & \\
\hline Income n (\%) & & & & 1 & & 30.18 & 0.001 & 0.37 \\
\hline$\leq \$ 2500 /$ month & $158(33.1)$ & $126(34.4)$ & $32(28.8)$ & & & & & \\
\hline$>\$ 2500 /$ month & 66 (13.8) & $28(7.7)$ & $38(34.2)$ & & & & & \\
\hline Missing & $253(53.0)$ & $212(57.9)$ & $41(36.9)$ & & & & & \\
\hline Weight concern n (\%) & & & & 4 & & 26.69 & 0.001 & 0.25 \\
\hline Not at all & $74(15.5)$ & $55(15.0)$ & $19(17.1)$ & & & & & \\
\hline Slightly & $111(23.3)$ & $96(26.2)$ & $15(13.5)$ & & & & & \\
\hline Somewhat & $77(16.1)$ & 69 (18.9) & $8(7.2)$ & & & & & \\
\hline Moderately & $67(14.0)$ & $43(11.7)$ & $24(21.6)$ & & & & & \\
\hline Extremely & $100(21.0)$ & $65(17.8)$ & $35(31.5)$ & & & & & \\
\hline Missing & $48(10.1)$ & $38(10.4)$ & $10(9.0)$ & & & & & \\
\hline Researcher-Estimated BMI n (\%) & & & & 2 & & 6.23 & 0.04 & 0.14 \\
\hline Underweight & $2(0.4)$ & $2(0.5)$ & $0(0.0)$ & & & & & \\
\hline Healthy weight & $84(17.6)$ & $56(15.3)$ & $28(25.2)$ & & & & & \\
\hline Overweight & $96(20.1)$ & $79(21.6)$ & $17(15.3)$ & & & & & \\
\hline Obese & $141(29.6)$ & $109(29.8)$ & $32(28.8)$ & & & & & \\
\hline Missing & $154(32.3)$ & $120(32.8)$ & $34(30.6)$ & & & & & \\
\hline Perceived body size-silhouette $n$ (\%) & & & & 2 & & 1.85 & 0.397 & 0.07 \\
\hline Underweight & $3(0.6)$ & $3(0.8)$ & $0(0.0)$ & & & & & \\
\hline Healthy weight & $147(30.8)$ & $111(30.3)$ & $36(32.4)$ & & & & & \\
\hline Overweight & $201(42.1)$ & $163(44.5)$ & $38(34.2)$ & & & & & \\
\hline Missing & & & & 1 & & 0.04 & 0.848 & 0.01 \\
\hline \multicolumn{9}{|l|}{$\begin{array}{l}\text { Medical weight problem Diagnosis } \mathrm{n} \\
(\%)\end{array}$} \\
\hline Yes & $148(31.0)$ & $116(31.7)$ & $32(28.8)$ & & & & & \\
\hline No & $236(49.5)$ & $183(50.0)$ & $53(47.7)$ & & & & & \\
\hline Missing & 93 (19.5) & 67 (18.3) & $26(23.4)$ & & & & & \\
\hline
\end{tabular}

\section{Results}

\section{Sample descriptive characteristics}

As shown in (Table 1), compared to Hispanic women $\left(M_{\text {age }}=40.3\right.$ years, $S D=13.2$ years), African American women $\left(\mathrm{M}_{\text {age }}=54.7\right.$ years, $S D=19.0$ years) were significantly older $[t(475)=7.44, p=0.001$, Hedge's $g=0.98$ ], and reported earning a higher monthly household income $\left[\chi^{2}(1, N=224)=30.18, p=0.001\right.$, Cramer's V=0.37]. Likewise, a higher percentage of African American women (53.1\%) indicated being moderately/extremely concerned about their weight, compared to $29.5 \%$ Hispanic women $\left[\chi^{2}(4, N=429)=26.69, p=0.001\right.$, Cramer's $\mathrm{V}=0.25]$. Although it is not shown in Table 1, most of the women ( $N=408,85.5 \%)$ reported visiting a doctor for self-health care in the previous 12 months. Of those women, just a third $(N=139,34.1 \%)$ reported receiving a weight problem diagnosis by a physician, even though $77 \%$ of Hispanic and $64 \%$ of African American women were classified as overweight/obese. Using logistic regression analysis, women with research-estimated BMI falling into the obesity category
(35.4\%) were significantly [Wald $\chi^{2}(1, N=176)=22.93, p<0.001$ ] more likely to have received a medical weight problem diagnosis than were women with researcher-estimated BMI falling into the overweight category $(11.8 \%)$. The odds ratio of receiving a medical weight problem diagnosis was 4.86 (95\% confidence interval of 2.55-9.29) times higher for women with research-estimated BMI falling into the obesity category than they were for women with researcher-estimated BMI falling into the overweight category. No significant ethnic differences were found in the proportion of Hispanic and African American women who reported having received a weight problem diagnosis $\left[\chi^{2}(1, N=384)=0.04, p=0.848\right.$, Cramer's V=0.01].

\section{Weight status}

Of 477 participating women, 324(68\%) women reported their height and weight. Based on researcher-estimated BMI, the majority of women were categorized as overweight and obese (Table 1). There were ethnic differences observed in the women's weight status distribution, with more African American women being classified as 
Table 2: Hierarchical Multiple Linear Regression Analysis for Variables Predicting Desire to be Thinner among Overweight and Obese Women ( $\mathrm{N}=176$ ).

\begin{tabular}{|c|c|c|c|c|c|c|c|c|c|c|c|c|c|c|c|}
\hline \multirow{2}{*}{ Variable } & \multicolumn{5}{|c|}{ Step 1} & \multicolumn{5}{|c|}{ Step 2} & \multicolumn{5}{|c|}{ Step 3} \\
\hline & B & SE B & $\beta$ & $t$ & $p$ & B & SE B & $\beta$ & $t$ & $p$ & B & SE B & $\beta$ & $t$ & $p$ \\
\hline Ethnicity ${ }^{a}$ & -0.87 & 0.23 & -0.26 & -3.75 & $<0.001$ & -0.84 & 0.23 & -0.25 & -3.67 & $<0.001$ & -0.64 & 0.34 & -0.19 & -1.9 & 0.059 \\
\hline Estimated BMI & 0.09 & 0.02 & 0.38 & 5.62 & $<0.001$ & 0.08 & 0.02 & 0.32 & 4.42 & $<0.001$ & 0.08 & 0.02 & 0.32 & 4.46 & $<0.001$ \\
\hline Weight concern & 0.22 & 0.07 & 0.22 & 3.16 & 0.002 & 0.19 & 0.07 & 0.19 & 2.68 & 0.008 & 0.19 & 0.07 & 0.19 & 2.64 & 0.009 \\
\hline $\begin{array}{l}\text { Medical weight } \\
\text { diagnosis }\end{array}$ & & & & & & 0.49 & 0.19 & 0.19 & 2.57 & 0.011 & 0.56 & 0.21 & 0.21 & 2.69 & 0.008 \\
\hline $\begin{array}{l}\text { Ethnicity }{ }^{*} \text { medical } \\
\text { weight diagnosis }^{b}\end{array}$ & & & & & & & & & & & -0.37 & 0.44 & -0.09 & -0.84 & 0.403 \\
\hline Overall Model $R^{2}$ & $0.24^{*+*}$ & & & & & $0.27^{* * *}$ & & & & & $0.27^{* * *}$ & & & & \\
\hline$F$ for change in $R^{2}$ & $18.11^{+*+*}$ & & & & & $6.61^{*}$ & & & & & 0.7 & & & & \\
\hline
\end{tabular}

${ }^{a}$ Ethnicity coded as $0=$ Hispanic and $1=$ African American.

${ }^{\mathrm{b}}$ Weight problem diagnosis coded as $\mathrm{No}=0$, Yes $=1$.

" $p<0.05, "$ "* $p<0.01,{ }^{* * *} p<0.001$

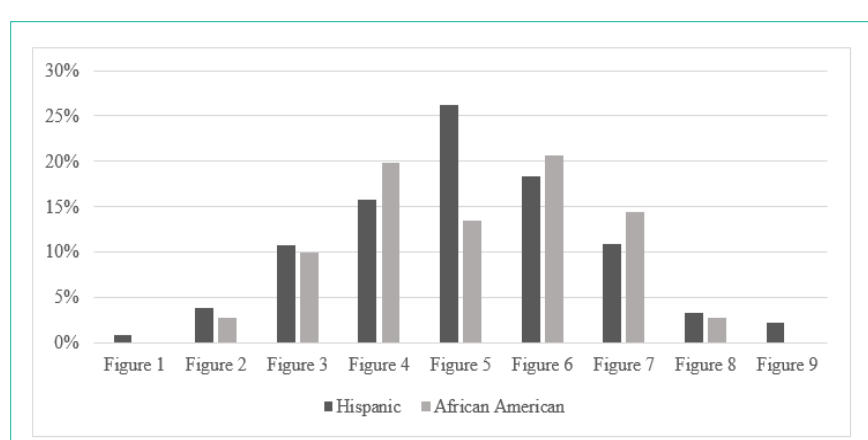

Figure 1: Perceived body size. This figure illustrates the distribution of Hispanic and African American women's perceived body size. $X^{2}(8, N=430)$ $=11.57, \mathrm{p}=0.17$, Cramer's $\mathrm{V}=0.16$.

having a healthy weight status than did Hispanic women. Hispanic women were more likely to be classified as being overweight or obese $\left[\chi^{2}(2, N=321)=6.23, p=0.04\right.$, Cramer's V=0.14]. Using the SFRS, most of the women $(81.2 \%)$ endorsed either silhouette 3 and 4 (healthy weight) or silhouette 5, 6 and 7 (overweight) to represent their current body size (Figure 1). There were no significant ethnic differences observed in participants' perceived weight status using the silhouettes $\left[\chi^{2}(8, N=430)=11.57, p=0.17\right.$, Cramer's V=0.16] (Figure 1).

\section{Ideal body size and body size dissatisfaction}

Overall, most of the women (66\%) endorsed either silhouette 3 or 4 (healthy weight) to represent their ideal body size (Figure 2). Ethnic differences were observed in Hispanic and African American women's selection of ideal body size figures $\left[\chi^{2}(7, N=436)=22.36\right.$, $p=0.002$, Cramer's $V=0.23$ ] (Figure 2). Hispanic women were more likely to select smaller ideal sizes compared to African American women. In terms of body size dissatisfaction (Figure 3), the majority of Hispanic (72.4\%) and African American (56.8\%) women desired to be one or more silhouette sizes thinner. A small percentage (4.4\%) of women had a desire to be heavier than their current weight. Hispanic women reported a greater desire to be thinner than did African American women $[t(419)=2.40, p=0.017]$.

\section{Relation of medical weight problem diagnosis to desire to be thinner}

As shown in Table 2, results of the hierarchical multiple linear regression analysis (including just the 176 women with researcherestimated overweight or obesity) revealed that at Step 1, ethnicity/

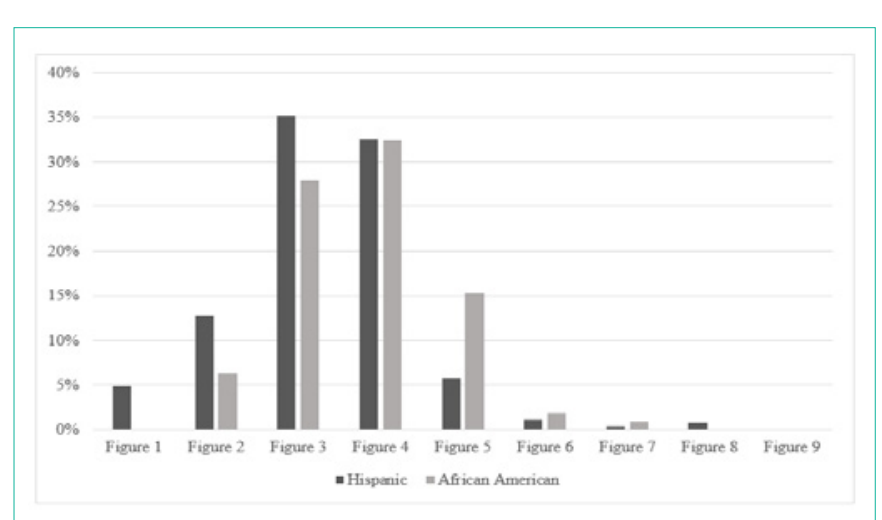

Figure 2: Ideal body size. This figure illustrates the distribution of Hispanic and African American women's ideal body size, $X^{2}(7, N=436)=22.36, p=$ 0.002 , Cramer's $V=0.23$.

race, researcher-estimated $\mathrm{BMI}$, and weight concern variables significantly contributed to the model, $(F(3,172)=18.11, p<0.001)$, and accounted for $24 \%$ of the variation in participants' desire to be thinner. Inspection of the beta coefficients indicated that Hispanic (coded as 0 ) women had a greater desire to be thinner than did African American (coded as 1$)$ women $(\beta=-0.26, p<0.001)$ and that a higher researcher-estimated BMI score was positively associated with greater desire to be thinner $(\beta=0.38, p<0.001)$. In addition, having a greater concern about one's weight was positively associated with a greater desire to be thinner $(\beta=0.22, p=0.002)$. The variable added in Step 2 (i.e., medical weight problem diagnosis) explained an additional $3 \%$ of variance in desire to be thinner $\left(\Delta \mathrm{R}^{2}=0.03\right.$, Fchange $(1,171)=6.61, p<0.001)$. After controlling for the other variables in the model, being Hispanic $(\beta=-0.25, p<0.001)$, having an increased researcher-estimated BMI $(\beta=0.32, p<0.001)$, and reporting greater weight concern $(\beta=0.19, p=0.008)$, and receiving a medical weight problem diagnosis $(\beta=0.19, p=0.011)$ were uniquely associated with an increased desire to be thinner. At Step 3 the interaction between medical weight problem and ethnicity/race was added to determine if the relation of medical weight problem diagnosis to desire to be thinner varied as a function of ethnicity/race. Results showed no significant interaction $\left[\Delta \mathrm{R}^{2}=0.00\right.$, Fchange $\left.(1,170)=0.70, p=0.403\right]$.

\section{Discussion}

Findings of this study indicate that only $34.1 \%$ of participating women reported receiving a weight problem diagnosis by a physician 


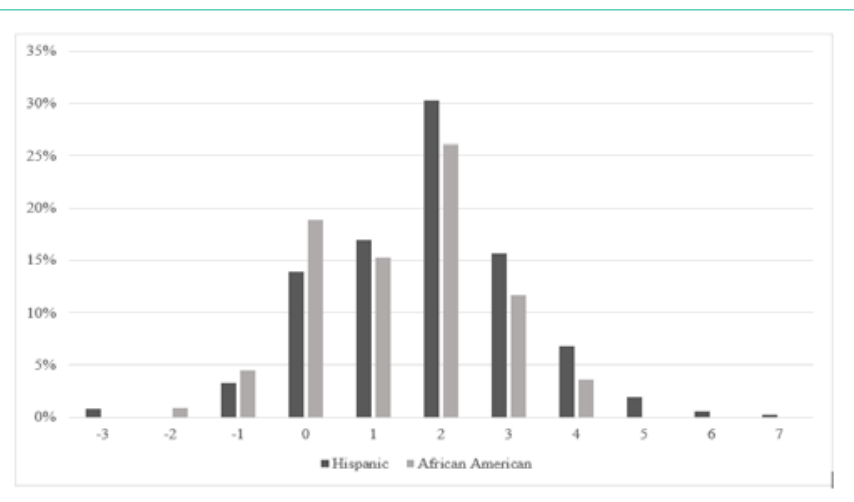

Figure 3: Body dissatisfaction. This figure illustrates the degree of body dissatisfaction among Hispanic and African American women as determined by subtracting the score for ideal body size from perceived body size, t (419) $=2.40, p=0.017$.

even though $77 \%$ of Hispanic and 64\% of African American women (based on their self-reported BMI) were classified as overweight/ obese.

Furthermore, women with obesity were more likely to report they had received a medical weight problem diagnosis compared to women with overweight. Similar proportions of Hispanic and African American women reported having received a medical weight problem diagnosis. Consistent with previous findings, a medical weight problem diagnosis was associated with the desire to be thinner among Hispanic and African American women with overweight/ obesity after controlling for other factors [5,21]. The current study's findings indicate that the importance of a medical weight problem diagnosis, for women with overweight/obese, extends to Hispanic and African American women.

In addition to the identified link between a medically diagnosed weight problem and desire to be thinner, results of this study indicated that being Hispanic, having a higher researcher-estimated $\mathrm{BMI}$, and reporting an increased weight concern, were also factors associated with desire to be thinner. Our study findings fill a gap in the literature by examining the contribution of a medically weight problem diagnosis along with several personal factors (researcherestimated BMI and weight concern), associated with the desire to be thinner among women. Previous research in this area has focused on examining binary associations between increased BMI and desire to be thinner;37,38 wanting to lose weight $[39,40]$; and between weight concern and a desire to be thinner, particularly among women with the highest BMI [41,42].

Despite African American women's greater weight concern, Hispanic women were more likely to report greater body dissatisfaction than did African American women. Consistent with previous studies [43-45], Hispanic women in this study endorsed smaller body sizes as ideal and were more likely to desire to be thinner when compared to their African American counterparts. This finding is consistent with previous research suggesting that African American women are more likely than Hispanic women to endorse heavier body size as ideal [46]. A potential explanation for our findings regarding ethnic/racial differences in ideal body size and desire to be thinner may be due to age differences in the sample. On average, in this study Hispanic women were 14 years younger than African American women and may have internalized a more idealized thin body size, leading them to an increased desire to lose weight $[47,48]$. In other body image studies, age has been negatively associated with higher levels of thinideal internalization, which suggests greater susceptibility to societal pressures for thinness among younger women $[49,50]$.

The study outcomes should be interpreted considering several limitations. First, the sample consisted of primarily Hispanic and African American women attending a health fair; thus, they may have been more weight-focused aimed at increasing weight loss, thus limiting the generalizability of results. Second, the cross-sectional nature of this study prohibits the assessment of bidirectional, or causal relationships. Future studies that utilize a longitudinal design are warranted to elucidate the temporal and the bidirectional nature of the relationship between medical weight problem diagnosis and desire to be thinner among minority women. Third, the small sample size, particularly of African American women, might limit the generalizability of results. Despite these limitations, this study contributes significantly to our understanding of the role of personal (internalized motivators) and medical weight problem diagnosis (externalized motivator) factors associated with desire to be thinner among minority women. Furthermore, our findings suggest a need for training of physicians on the importance of providing Hispanic and African American women with a weight status diagnosis along with specific parameters of what constitutes an overweight and/ or obesity status. In addition, physicians should receive training to utilize different modalities to distinguish different obesity status (e.g., providing verbal and written definitions of overweight and obesity and providing a pictorial stimulus). Furthermore, medical professionals should receive training about asking minority women about weight concerns and other factors (e.g., ideal healthy body size) that might affect their desire to be thinner in order to tailor their consultations regarding overweight and obesity.

\section{References}

1. Ogden CL, Carroll MD, Lawman HG, Fryar CD, Kruszon-Moran D, Kit BK et al. Trends in obesity prevalence among children and adolescents in the United States, 1988-1994 through 2013-2014. JAMA. 2016; 315: 2292-2299.

2. Hales $C M$, Carroll MD, Fryar CD, Ogden CL. Prevalence of obesity among adults and youth: United States, 2015-2016. NCHS Data Brief. 2017; 288: 1-8.

3. Taylor VH, Forhan M, Vigod SN, Mclntyre RS, Morrison KM. The impact of obesity on quality of life. Best Pract Res Clin Endocrinol Metab. 2013; 27: 139-146.

4. Kolotkin RL, Andersen JR. A systematic review of reviews: Exploring the relationship between obesity, weight loss, and health-related quality of life. Clin Obes. 2017; 7: 273-289.

5. Bleich SN, Pickett-Blakely O, Cooper LA. Physician practice patterns of obesity diagnosis and weight-related counseling. Patient Educ Couns. 2011; 82: $123-129$

6. Cefalu WT, Bray GA, Home PD, Garvey WT, Klein S, Pi-Sunyer FX, et al. Advances in the science, treatment, and prevention of the disease of obesity: reflections from a diabetes care editors' expert forum. Diabetes Care. 2015; 38: 1567-1582.

7. Dewhurst A, Peters S, Devereux-Fitzgerald A, Hart J. Physicians' views and experiences of discussing weight management within routine clinical consultations: A thematic synthesis. Patient Educ Couns. 2017; 100: 897908. 
8. Kaplan LM, Golden A, Jinnett K, Kolotkin RL, Kyle TK, Look M, et al. Perceptions of barriers to effective obesity care: Results from the national ACTION study. Obesity (Silver Spring). 2018; 26: 61-69.

9. Sumithran P, Proietto J. The defense of body weight: A physiological basis for weight regain after weight loss. Clin Sci (Lond). 2013; 124: 231-241.

10. Bleich SN, Bennett WL, Gudzune KA, Cooper LA. Impact of physician BMI on obesity care and beliefs. Obesity (Silver Spring). 2012; 20: 999-1005.

11. Miller EO, Stanistreet B, Ruckdeschel E, Nead K, Fortuna RJ. Factors associated with the accurate diagnosis of obesity. J Community Health. 2016; 41: $1257-1263$

12. Dilley KJ, Martin LA, Sullivan C, Seshadri R, Binns HJ. Identification of overweight status is associated with higher rates of screening for comorbidities of overweight in pediatric primary care practice. Pediatrics. 2007; 119: e148-e155.

13. Post RE, Mainous AG $3^{\text {rd }}$, Gregorie SH, Knoll ME, Diaz VA, Saxena SK. The influence of physician acknowledgment of patients' weight status on patien perceptions of overweight and obesity in the United States. Arch Intern Med. 2011; 171: 316-321.

14. Forhan $M$, Risdon $C$, Solomon $P$. Contributors to patient engagement in primary health care: Perceptions of patients with obesity. Prim Health Care Res Dev. 2013; 14: 367-372.

15. Greiner KA, Born W, Hall S, Hou Q, Kimminau KS, Ahluwalia JS. Discussing weight with obese primary care patients: Physician and patient perceptions. J Gen Intern Med. 2008; 23: 581-587.

16. Block JP, DeSalvo KB, Fisher WP. Are physicians equipped to address the obesity epidemic? Knowledge and attitudes of internal medicine residents. Prev Med. 2003; 36: 669-675

17. Forman-Hoffman $\mathrm{V}$, Little A, Wahls T. Barriers to obesity management: A pilot study of primary care clinicians. BMC Fam Pract. 2006; 7: 35.

18. Foster GD, Wadden TA, Makris AP, Davidson D, Sanderson RS, Allison DB et al. Primary care physicians' attitudes about obesity and its treatment. Obes Res. 2003; 11: 1168-1177.

19. Heintze C, Metz U, Hahn D, Niewohner J, Schwantes U, Wiesner J, et al. Counseling overweight in primary care: An analysis of patient-physician encounters. Patient Educ Couns. 2010; 80: 71-75.

20. Sikorski C, Luppa M, Glaesmer H, Brähler E, Konig HH, Riedel-Heller SG. Attitudes of health care professionals towards female obese patients. Obes Facts. 2013; 6: 512-522.

21. Rose SA, Poynter PS, Anderson JW, Noar SM, Conigliaro J. Physician weight loss advice and patient weight loss behavior change: A literature review and meta-analysis of survey data. Int J Obes (Lond). 2013; 37: 118-128.

22. Byrd AS, Toth AT, Stanford FC. Racial disparities in obesity treatment. Curr Obes Rep. 2018; 7: 130-138.

23. Ko JY, Brown DR, Galuska DA, Zhang J, Blanck HM, Ainsworth BE. Weight loss advice U.S. obese adults receive from health care professionals. Prev Med. 2008; 47: 587-592.

24. Fryar CD, Carroll MD, Ogden CL. Prevalence of overweight, obesity, and severe obesity among adults aged 20 and over: United States, 1960-1962 through 2015-2016. National Center for Health Statistics. 2018.

25. Agyemang P, Powell-Wiley TM. Obesity and Black women: Special considerations related to genesis and therapeutic approaches. Curr Cardiovasc Risk Rep. 2013; 7: 378-386.

26. Choi J, Bender MS, Arai S, Fukuoka Y. Factors associated with underestimation of weight status among Caucasian, Latino, Filipino, and Korean Americans-DiLH Survey. Ethn Dis. 2015; 25: 200-207.

27. Moore SE, Harris C, Wimberly Y. Perception of weight and threat to health. J Natl Med Assoc. 2010; 102: 119-124.

28. Hendley Y, Zhao L, Coverson DL, Din-Dzietham R, Morris A, Quyyumi AA et al. Differences in weight perception among Blacks and Whites. J Womens Health (Larchmt). 2011; 20: 1805-1811.
29. Neal D, Magwood G, Jenkins C, Hossler CL. Racial disparity in the diagnosis of obesity among people with diabetes. J Health Care Poor Underserved. 2006; 17: 106-115.

30. Johnson F, Wardle J. Dietary restraint, body dissatisfaction, and psychological distress: A prospective analysis. J Abnorm Psychol. 2005; 114: 119-125.

31. Yost J, Krainovich-Miller B, Budin W, Norman R. Assessing weight perception accuracy to promote weight loss among US female adolescents: A secondary analysis. BMC Public Health. 2010; 10: 1-11.

32. Bowring AL, Peeters A, Freak-Poli R, Lim MS, Gouillou M, Hellard M Measuring the accuracy of self-reported height and weight in a communitybased sample of young people. BMC Med Res Methodol. 2012; 12: 175-182.

33. Olfert MD, Barr ML, Charlier CM, Famodu OA, Zhou W, Mathews AE, et al. Self-reported vs. measured height, weight, and BMI in young adults. Int J Environ Res Public Health. 2018; 15: 2216-2224.

34. Stunkard AJ, Sørensen T, Schulsinger F. Use of the Danish adoption register for the study of obesity and thinness. Res Publ Assoc Res Nerv Ment Dis. 1983; 60: 115-120.

35. Bulik CM, Wade TD, Heath AC, Martin NG, Stunkard AJ, Eaves LJ. Relating body mass index to figural stimuli: Population-based normative data for Caucasians. Int J Obes Relat Metab Disord. 2001; 25: 1517-1524.

36. Thompson JK, Altabe MN. Psychometric qualities of the figure rating scale. Int J Eat Disord. 1991; 10: 615-619.

37. Prioreschi A, Wrottesley SV, Cohen E, Reddy A, Said-Mohamed R, Twine R, et al. Examining the relationships between body image, eating attitudes, BMI, and physical activity in rural and urban South African young adult females using structural equation modeling. PLoS One. 2017; 12: e0187508.

38. Radwan $\mathrm{H}$, Hasan $\mathrm{HA}$, Ismat $\mathrm{H}$, Hakim $\mathrm{H}$, Khalid $\mathrm{H}$, Al-Fityani L, et al. Body mass index perception, body image dissatisfaction, and their relations with weight-related behaviors among university students. Int J Environ Res Public Health. 2019; 16: 1541-1551.

39. Jackson SE, Wardle J, Johnson F, Finer N, Beeken RJ. The impact of a health professional recommendation on weight loss attempts in overweight and obese British adults: A cross-sectional analysis. BMJ Open. 2013; 3: e003693.

40. Yaemsiri S, Slining MM, Agarwal SK. Perceived weight status, overweight diagnosis, and weight control among US adults: The NHANES 2003-2008 Study. Int J Obes (Lond). 2011; 35: 1063-1070.

41. Okop KJ, Mukumbang FC, Mathole T, Levitt N, Puoane T. Perceptions of body size, obesity threat and the willingness to lose weight among Black South African adults: A qualitative study. BMC Public Health. 2016; 16: 365377.

42. Wardle J, Johnson F. Weight and dieting: Examining levels of weight concern in British adults. Int J Obes Relat Metab Disord. 2002; 26: 1144-1149.

43. Fitzgibbon ML, Spring B, Avellone ME, Blackman LR, Pingitore R, Stolley MR. Correlates of binge eating in Hispanic, Black, and White women. Int J Eat Disord. 1998; 24: 43-52.

44. Sánchez-Johnsen LA, Fitzgibbon ML, Martinovich Z, Stolley MR, Dyer AR, Van Horn L. Ethnic differences in correlates of obesity between LatinAmerican and Black women. Obes Res. 2004; 12: 652-660.

45. Warren CS. Body area dissatisfaction in White, Black and Latina female college students in the USA: An examination of racially salient appearance areas and ethnic identity. Ethn Racial Stud. 2014; 37: 537-556.

46. Mama SK, Quill BE, Fernandez-Esquer ME, Reese-Smith JY, Banda JA, Lee RE. Body image and physical activity among Latina and African American women. Ethn Dis. 2011; 21: 281-287.

47. Haytko DL, Parker RS, Motley CM, Torres IM. Body image and ethnicity: A qualitative exploration. J Mark Manag. 2014; 17: 1-20.

48. Kraeplin CR. Minority females \& the thin ideal: Ethnic versus mainstream fashion magazines and their effects on acculturation \& body image in young Black \& Latino women. J Res Women Gend. 2011; 2: 50-82. 
49. Pruis TA, Janowsky JS. Assessment of body image in younger and older women. J Gen Psychol. 2010; 137: 225-238.
50. Kilpela LS, Becker CB, Wesley N, Stewart T. Body image in adult women: Moving beyond the younger years. Adv Eat Disord. 2015; 3: 144-164. 